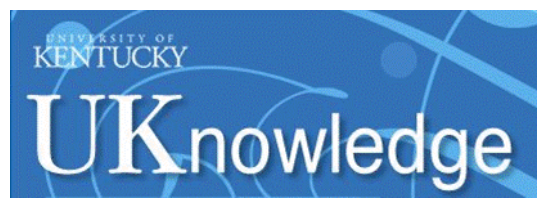

University of Kentucky

UKnowledge

\title{
Microglial-Associated Responses to Comorbid Amyloid Pathology and Hyperhomocysteinemia in an Aged Knock-in Mouse Model of Alzheimer's Disease
}

\author{
David J. Braun \\ University of Kentucky, david.braun1@uky.edu \\ Edgardo R. Dimayuga \\ University of Kentucky, edgardo.dimayuga@uky.edu \\ Josh M. Morganti \\ University of Kentucky, josh.morganti@uky.edu \\ Linda J. Van Eldik \\ University of Kentucky, linda.vaneldik@uky.edu
}

Follow this and additional works at: https://uknowledge.uky.edu/sbcoa_facpub

Part of the Geriatrics Commons, and the Neurosciences Commons

Right click to open a feedback form in a new tab to let us know how this document benefits you.

\section{Repository Citation}

Braun, David J.; Dimayuga, Edgardo R.; Morganti, Josh M.; and Van Eldik, Linda J., "Microglial-Associated Responses to Comorbid Amyloid Pathology and Hyperhomocysteinemia in an Aged Knock-in Mouse Model of Alzheimer's Disease" (2020). Sanders-Brown Center on Aging Faculty Publications. 140. https://uknowledge.uky.edu/sbcoa_facpub/140

This Article is brought to you for free and open access by the Aging at UKnowledge. It has been accepted for inclusion in Sanders-Brown Center on Aging Faculty Publications by an authorized administrator of UKnowledge. For more information, please contact UKnowledge@lsv.uky.edu. 


\title{
Microglial-Associated Responses to Comorbid Amyloid Pathology and Hyperhomocysteinemia in an Aged Knock-in Mouse Model of Alzheimer's Disease
}

\author{
Digital Object Identifier (DOI) \\ https://doi.org/10.1186/s12974-020-01938-7
}

Notes/Citation Information

Published in Journal of Neuroinflammation, v. 17, issue 1, article no: 274.

(c) The Author(s). 2020

This article is licensed under a Creative Commons Attribution 4.0 International License, which permits use, sharing, adaptation, distribution and reproduction in any medium or format, as long as you give appropriate credit to the original author(s) and the source, provide a link to the Creative Commons licence, and indicate if changes were made. The images or other third party material in this article are included in the article's Creative Commons licence, unless indicated otherwise in a credit line to the material. If material is not included in the article's Creative Commons licence and your intended use is not permitted by statutory regulation or exceeds the permitted use, you will need to obtain permission directly from the copyright holder. To view a copy of this licence, visit https://creativecommons.org/licenses/by/4.0/. The Creative Commons Public Domain Dedication waiver (https://creativecommons.org/publicdomain/zero/ $1.0 /$ ) applies to the data made available in this article, unless otherwise stated in a credit line to the data. 


\title{
Microglial-associated responses to comorbid amyloid pathology and hyperhomocysteinemia in an aged knock-in mouse model of Alzheimer's disease
}

\author{
David J. Braun ${ }^{1 *}$, Edgardo Dimayuga', Josh M. Morganti ${ }^{1,2,3}$ and Linda J. Van Eldik ${ }^{1,2,3^{*}}$ (D)
}

\begin{abstract}
Background: Elevated blood homocysteine levels, termed hyperhomocysteinemia (HHcy), is a prevalent risk factor for Alzheimer's disease (AD) in elderly populations. While dietary supplementation of B-vitamins is a generally effective method to lower homocysteine levels, there is little if any benefit to cognition. In the context of amyloid pathology, dietary-induced HHcy is known to enhance amyloid deposition and certain inflammatory responses. Little is known, however, about whether there is a more specific effect on microglia resulting from combined amyloid and HHcy pathologies.

Methods: The present study used a knock-in mouse model of amyloidosis, aged to 12 months, given 8 weeks of Bvitamin deficiency-induced HHcy to better understand how microglia are affected in this comorbidity context.

Results: We found that HHcy-inducing diet increased amyloid plaque burden, altered the neuroinflammatory milieu, and upregulated the expression of multiple damage-associated and "homeostatic" microglial genes.

Conclusions: Taken together, these data indicate complex effects of comorbid pathologies on microglial function that are not driven solely by increased amyloid burden. Given the highly dynamic nature of microglia, their central role in $A D$ pathology, and the frequent occurrence of various comorbidities in AD patients, it is increasingly important to understand how microglia respond to mixed pathological processes.
\end{abstract}

Keywords: Alzheimer's disease, Amyloid, Homocysteine, Hyperhomocysteinemia, Microglia, Neuroinflammation

\section{Background}

Homocysteine (Hcy) is an intermediary in essential cellular pathways, and its metabolism depends on several vitamin cofactors, primarily $\mathrm{B}_{6}, \mathrm{~B}_{9}$ (folic acid), and $\mathrm{B}_{12}$. Deficiencies in one or more of these are therefore a common cause of elevated blood homocysteine, termed hyperhomocysteinemia (HHcy) [1]. Evidence indicates that both elevated homocysteine itself, and the broader

\footnotetext{
*Correspondence: david.braun1@uky.edu; linda.vaneldik@uky.edu 'Sanders-Brown Center on Aging, University of Kentucky, 101 Sanders-Brown Bldg., 800 S. Limestone Street, Lexington, KY 40536, USA

Full list of author information is available at the end of the article
}

metabolic dysfunctions resulting from B-vitamin deficiency, are relevant to its status as a vascular risk factor and risk factor for Alzheimer's disease (AD) [2-4]. The normal human range for Hcy in plasma is generally considered to be less than $15 \mu \mathrm{M}$, with increasing levels categorized as moderate $(15-30 \mu \mathrm{M})$, intermediate (30$100 \mu \mathrm{M})$, or severe $(>100 \mu \mathrm{M})$ HHcy. Although the prevalence of HHcy in the general population is estimated to be around $5 \%$, it is significantly higher in the elderly [5], a population in which B-vitamin status is a major contributor to HHcy [6]. Interestingly, elderly men have been found to have elevated plasma 
homocysteine compared to women [7], while $\mathrm{AD}$ is more common in women [8], highlighting that HHcy is only one in a complex array of factors influencing any given individual's risk of dementia. Nonetheless, the population attributable risk of dementia from raised Hcy is estimated to be between 4 and $31 \%$; in other words, preventing HHcy could prevent somewhere between 1 in 25 to 1 in 3 cases of $\mathrm{AD}$ [9]. In the USA alone, even the conservative estimate would translate to hundreds of thousands of people. It follows, then, that reduction of HHcy in the population is an attractive goal. In addition to lifestyle modifications (e.g., quitting smoking, exercise), B-vitamin supplementation is a fairly straightforward intervention that reduces circulating Hcy levels and thus the prevalence of HHcy [10]. Encouragingly, since the USS began supplementing grain with folic acid in the late 1990's, the prevalence of HHcy has roughly halved [11], and this could potentially be a contributor to the recently reported reductions in the rate of increase in AD incidence [12]. Nonetheless, correcting the acute metabolic dysfunctions underlying elevated Hcy appears to be a necessary but insufficient step to abrogate the full contribution of this risk factor to $\mathrm{AD}$ associated cognitive decline [9], and adjunct treatments will likely be important moving forward.

HHcy-related neural dysfunction is a multifactorial pathological process, mediated by complex and interacting pathways related to oxidative damage, inflammation, hypomethylation, and others [13]. In this regard, it shares commonalities with $\mathrm{AD}$, and there may be important points of convergence amenable to therapeutic targeting. Recent work has highlighted the role of microglia as a nexus in the development and progression of AD pathology (for review see [14]), with particular focus on a shift of microglia from a more "homeostatic" phenotype to a damage-associated or neurodegenerative (DAM) phenotype $[15,16]$. The microglial responses to pathological Hcy elevation are less well-characterized, but there is evidence that homocysteine directly increases activation of microglial-type cells in vitro [17, 18], and both direct Hcy supplementation [19] and vitamin deficiency-induced HHcy have similar impacts in vivo [20-22]. Microglial dysregulation could therefore represent an important convergence point in the context of comorbid HHcy and amyloid pathology. There are several major possibilities here that are relevant from a treatment standpoint and not mutually exclusive: the comorbidity context accentuates dysfunctional microglial responses to amyloid, it induces more of the microglia to assume a dysfunctional DAM state, or it causes some emergent alteration unique to these comorbid pathologies. The goal of the present study is to better understand these possibilities by using a knock-in (KI) mouse model of amyloidosis with mutant presenilin 1 and amyloid precursor protein transgenes under control of endogenous promoters to avoid potential overexpression artifacts [23]. Male and female mice aged 12 months were placed on B-vitamin deficient diet for 8 weeks, with the effect on various neuroinflammatory and microglial parameters characterized at the conclusion of dietary administration, when mice were about 14 months old. We found that elevation of homocysteine level in the context of amyloid pathology enhances parenchymal plaque deposition, subtly alters the neuroinflammatory milieu, and influences a number of genes important to microglial functioning. Interestingly, these changes are consistent with both an increase in DAM microglia as well as some emergent effects on microglia-relevant pathways. This study lays the groundwork for follow-up experiments making use of cell-specific isolation and next generation sequencing technologies.

\section{Methods}

\section{Animals and experimental design}

All mice were housed 1-5 per cage (503.22 usable $\mathrm{cm}^{2}$ ) in a room at $23^{\circ} \mathrm{C} \pm 2{ }^{\circ} \mathrm{C}$, under a 14/10-h light/dark cycle beginning at 6:00 AM, with ad libitum access to water and chow. The $\mathrm{APP}^{\mathrm{NLh} / \mathrm{NLh}} \times \mathrm{PS}^{\mathrm{P} 264 \mathrm{~L} / \mathrm{P} 264 \mathrm{~L}}$ double knock-in (KI) mouse model expresses humanized amyloid precursor protein with the Swedish mutation (K670N/M671L), along with a P264L point mutation in the mouse presenilin 1 gene [24]. The homozygous KI mice were maintained on a combined CD-1/129 background, with wildtype (WT) controls derived separately from matings of heterozygous KI animals. The experiment was carried out in a $2 \times 2$ diet by genotype design, where half the mice of each genotype were randomized to receive 8 weeks of control (Envigo, \#TD.01636) or HHcy diet (Envigo, \#TD.97345), beginning between 52 and 54 weeks of age $(M=53.4$ weeks, $\mathrm{SD}=0.36)$. The HHcy diet was deficient in vitamins B6, B9, and B12 and supplemented with excess methionine, while the control diet was nutritionally matched with normal methionine and B-vitamin levels [25]. Humane-endpoint criteria were $20 \%$ weight loss across the study or $10 \%$ weight loss within two weeks, along with detrimental changes in body condition (e.g., lethargy, hunched posture, dehydration, dermatitis). None of the mice reached humaneendpoint criteria; however, three mice died during the study and were excluded from all analyses: one KI female receiving HHcy diet, one WT male receiving control diet, and one WT male receiving HHcy diet. Importantly, mice were randomized irrespective of sex, resulting in an imbalance in the final sex ratios. The final numbers of mice for each group were $8 \mathrm{WT}$ on control diet ( 5 female and 3 male), 10 WT on HHcy diet ( 5 female and 5 male), $11 \mathrm{KI}$ on control diet (4 female and 7 male), and $10 \mathrm{KI}$ on HHcy diet (8 female and 2 male). 
As the experiment was not powered to detect sex differences, it should be noted that the imbalance may have increased experimental variability and thus reduced statistical power, or otherwise influenced the data. The experiment was performed in compliance with the Institutional Animal Care and Use Committee of the University of Kentucky.

\section{Tissue collection and blood analyses}

Mice were deeply anesthetized with 5\% isoflurane, and arterial blood collected from the left ventricle and placed into EDTA-plasma tubes (Greiner Bio-One, \#454428) for separation of plasma by centrifugation $(2000 \times g$ for $20 \mathrm{~min}$ at room temperature) followed by storage at $80^{\circ} \mathrm{C}$. As an interim analysis to verify the expected dietary effects, a subset of 7 WT mice (4 on HHcy and 3 on control diet) had whole blood taken for hematologic analysis using i-STAT CG8+ cartridges (Abbott Laboratories) according to the manufacturer's instructions. Additionally, at the conclusion of the full study, plasma samples from a randomly chosen subset of 5 mice per group (20 total) were diluted 1:5 in ARCHITECT MultiAssay Manual Diluent (Abbott Laboratories, Chicago, IL, USA) and delivered to the University of Kentucky Clinical Laboratory for Hcy measurement on an ARCHITEC $\mathrm{T}$ i2000SR analyzer (Abbott Laboratories). Samples were diluted to reach the volume requirements for the assay $(500 \mu \mathrm{L})$. The lower limit of detection is $1 \mu \mathrm{M}$, and diluted samples reading less than 1 do not give an output value. Samples with an output value $>1 \mu \mathrm{M}$ were multiplied by the dilution factor to determine the total homocysteine concentration in the undiluted plasma. None of the diluted samples from mice on control diet gave a reading of greater than $1 \mu \mathrm{M}$.

All mice subsequently underwent transcardial perfusion with $50 \mathrm{ml}$ ice-cold phosphate-buffered saline (PBS) at a flow rate of $10 \mathrm{ml} / \mathrm{min}$ before decapitation and brain removal and dissection. The right hemisphere was postfixed in $4 \%$ paraformaldehyde for $24 \mathrm{~h}$ at $4{ }^{\circ} \mathrm{C}$ and cryoprotected in $30 \%$ sucrose for at least $48 \mathrm{~h}$ at $4{ }^{\circ} \mathrm{C}$. Samples were subsequently cut into $30 \mu \mathrm{m}$ sections with a sliding microtome and stored in cryoprotectant solution at $-20^{\circ} \mathrm{C}$ prior to immunofluorescent staining. The hippocampus and overlying cortex were dissected from the left hemisphere, flash frozen in liquid nitrogen, and stored at $-80^{\circ} \mathrm{C}$ until processing for biochemical endpoints described below. The cortex was divided in two: a more caudal piece directly overlying the hippocampus was used for protein analysis. An adjacent rostral piece was used for mRNA expression analysis. A portion of dorsal hippocampus was used for protein analysis. See supplement 1 for an illustration of brain regions dissected and outlined for analysis.

\section{Immunofluorescence}

Staining was performed on free-floating sections spaced approximately 300 apart through the dorsal hippocampus and overlying cortex, for a total of 6-8 sections per animal. Blocking was performed with $10 \%$ normal goat serum (Lampire Biological Laboratories, \#7332500) and $0.2 \%$ Triton X-100 in PBS. All antibodies were diluted in PBS with $3 \%$ normal goat serum and $0.2 \%$ Triton X-100. Sections were incubated overnight at $4{ }^{\circ} \mathrm{C}$ with rabbit anti-P2ry12 (1:500, Anaspec \#AS-55043A) and mouse anti-A $\beta$ 6E10 conjugated to Alexa 647 (1:200, BioLegend $\# 803021$ ). Samples were subsequently incubated at room temperature for $2 \mathrm{~h}$ in 1:500 secondary antibody solution with Alexa 488 goat anti-rabbit (Invitrogen, \#A-11034). Sections were mounted and treated for 5 min with $1 \mathrm{x}$ TrueBlack (VWR, \#10119-144) in 70\% ethanol to reduce autofluorescence before drying and coverslipping in Vectashield mounting medium with DAPI (Vector Laboratories, \#H-1200). Entire slides were imaged on a Zeiss Axio Scan Z1 digital slide scanner at $\times 20$ magnification.

\section{Image analysis}

The dorsal hippocampus and overlying cortex were manually outlined in the HALO analysis suite (Indica Labs, version 2.3.2089.34) by an investigator blinded to experimental groups. The algorithm minimum intensity settings for all analyses were manually thresholded based upon negative control (no primary antibody). For cortical and hippocampal analyses of P2ry12 staining, and P2ry12 and 6E10 co-localization, the positive pixel algorithm (Area Quantification FL v1.2) was applied to the traced region across all sections per animal to give a single value of total percent area stained per region per mouse. For cortical and hippocampal analyses of $6 \mathrm{E} 10$ staining, the object counter algorithm (Object Colocalization FL v1.0) was applied to the traced region across all sections to give a single average count per square millimeter of tissue per region. Minimum object size was set to $10 \mu \mathrm{m}^{2}$. Plaque size distributions were analyzed in two ways. First, plaques were binned into small $\left(<300 \mu \mathrm{m}^{2}\right)$, medium (301 to $\left.900 \mu \mathrm{m}^{2}\right)$ and large (901+ $\left.\mu \mathrm{m}^{2}\right)$ size ranges. Arbitrary cutoff points were based on a previous study of this model [26], and the average number of plaques $/ \mathrm{mm}^{2}$ within each bin were determined per animal and compared between diet groups. Second, cumulative size distribution curves were generated for each diet by treating each plaque as an individual data point within each dietary condition, and testing the curves for difference with the Kolmogorov-Smirnov test [27]. For the spatial analysis of microglia around amyloid plaques, 1-4 individual plaques were manually circled per section within the outlined cortical region, totaling 15 plaques per animal or 120 per diet condition. This number was based upon the plaque sampling rate 
used in the previous reference [24] of about 100 per condition. The circle annotation tool was used to manually circle the entirety of the plaque, and 3 outward concentric partitions added with a fixed width of $30 \mu \mathrm{m}$. The positive pixel algorithm was applied within each ring (inner, middle, and outer). To be selected, plaques had to be far enough away from tissue edges or other plaques to enable non-overlapping ROIs completely contained within the tissue. The semi-randomly selected plaques had a significantly larger median size $\left(215.6 \mu \mathrm{m}^{2}\right)$ than the full distribution $\left(51.5 \mu \mathrm{m}^{2}\right)$, likely because the smallest plaques tended to be more clustered and therefore not amenable to this analysis. Nonetheless, the median size of the plaques analyzed did not differ between the control $\left(293.7 \mu \mathrm{m}^{2}\right)$ or HHcy $\left(219.8 \mu \mathrm{m}^{2}\right)$ dietary groups (two-tailed Mann-Whitney $U, p=0.235)$. The cumulative size distributions of the circled plaques were also not significantly different between the two groups (Kolmogorov-Smirnov, $D=0.099$, $p=0.482$ ).

\section{MesoScale Discovery (MSD) multiplex ELISA}

Pieces of the dissected hippocampus and cortex from the left hemisphere were used that approximate the regions outlined for the immunofluorescence analyses in the right hemisphere. Tissues from each mouse were homogenized using an Omni Bead Ruptor 24 (Omni International) at a 1:20 weight to volume ratio in lysis buffer: PBS with $1 \mathrm{mM}$ PMSF, $0.5 \mathrm{mM}$ EDTA and $0.2 \mathrm{X}$ Halt Protease Inhibitor Cocktail (Thermo Scientific, \#87786). Homogenates were centrifuged at $12,000 \times g$ for $20 \mathrm{~min}$ at $4{ }^{\circ} \mathrm{C}$. Supernatants were collected for cytokine or $\mathrm{A} \beta_{1-40}$ $(\mathrm{A} \beta 40) / \mathrm{A} \beta_{1-42}(\mathrm{~A} \beta 42)$ measurement using MSD custom mouse V-Plex ELISA kits and a human $6 \mathrm{E} 10 \mathrm{~A} \beta$ kit (K15200E), respectively. IL-1 $\beta$, IL-6, TNF $\alpha$, and CXCL1 were run multiplexed as part of the Proinflammatory Panel 1 Mouse Kit (K15048). CCL3 and IL-33 were separately run multiplexed as part of the Cytokine Panel 1 Mouse Kit (K15245). All samples were run undiluted. For the cytokines, samples were incubated overnight at $4{ }^{\circ} \mathrm{C}$. Samples were incubated for $2 \mathrm{~h}$ at room temperature for the $A \beta$ kit. Cytokine levels and $A \beta$ peptide levels were normalized to the total milligrams (mg) of protein loaded in the sample as determined by BCA Protein Assay (ThermoFisher \#23225).

\section{Quantitative reverse-transcriptase polymerase chain reaction (qRT-PCR)}

RNA was isolated from the cortical tissue piece just rostral to that used for protein extraction with the RNeasy Plus Mini Kit (Qiagen, \#74136) according to the manufacturer's instructions. Tissue was weighed and homogenized in an appropriate volume of buffer, and genomic DNA removed with the gDNA eliminator column. The samples were mixed with $70 \%$ ethanol, run through the RNeasy column, washed, and eluted in RNase-free water. Quantity and quality of RNA and 260/280 absorbance ratios were assessed using a NanoDrop spectrophotometer (ThermoFisher Scientific). Reverse transcription was performed with the High Capacity cDNA Reverse Transcription kit (Applied Biosystems, \#4368814) according to the manufacturer's protocol. Real-time PCR was performed on a ViiA 7 Real-Time PCR System (Applied Biosystems) using individual TaqMan $^{\circ}$ probes for P2ry12, Clec7a, and Itgax and custom TaqMan Array Cards (ThermoFisher Scientific, \#4342253) with TaqMan Fast Advanced Master Mix (ThermoFisher Scientific, \#4444557). See Table 1 for a complete list of genes and probes included on the array. Established microglial markers affected by amyloid pathology were chosen based on recent studies $[15,16]$. Relative gene expression was calculated using the $2^{-\triangle \Delta C T}$ method and $\log 2$ normalized. HPRT and $18 \mathrm{~S}$ were used as housekeeping genes for the individual probes and the custom array, respectively.

\section{Statistical analysis, figure generation, and reporting}

Analyses and figure generation were performed with JMP Pro 14 (SAS) and Prism 8.3.0 (GraphPad). Two-way analysis of variance (ANOVA) with Sidak's or Dunnett's post hoc testing, student's $t$ tests, or non-parametric Mann-Whitney $U$ tests as indicated in the figure legends or text. For plaque size analysis, Kolmogorov-Smirnov tests were used to determine whether the cumulative plaque size distributions differed between dietary groups. For the gene expression data, three group comparisons were made: WT HHcy versus WT control, KI control vs WT control, and KI HHcy versus KI control. To generate the heatmap, group scores were averaged and transformed into $z$-scores using JMP; then, the variable clustering script was run to group genes by similarity of expression pattern prior to visualization in Prism. Where reported in the text, group means are followed by the standard deviation (SD).

\section{Results \\ Eight weeks of B-vitamin-deficient and methionine- supplemented diet induces HHcy and increases plaque deposition in the KI mice}

The average plasma homocysteine levels after HHcy diet were similar between genotypes, with WT mice achieving an average concentration of $19.0 \mu \mathrm{M}(\mathrm{SD}=6.8 \mu \mathrm{M})$ versus $14.7 \mu \mathrm{M}(\mathrm{SD}=2.8 \mu \mathrm{M})$ in the $\mathrm{KI}$ animals (for full dietary validation data see supplement 2 ). The plasma samples from all mice on control diet were below the limit of detection for the test after dilution-meaning the undiluted samples were less than $5 \mu \mathrm{M}$-consistent with what has been reported in the literature by 
Table 1 Gene names and TaqMan probes analyzed in this study. Genes in bold were run with individual probes: the rest were run together on TaqMan custom low-density array cards

\begin{tabular}{|c|c|}
\hline Gene & TaqMan probe \\
\hline Apoe & Mm01307193_g1 \\
\hline $\mathrm{B} 2 \mathrm{~m}$ & Mm00437762_m1 \\
\hline C1qa & Mm00432142_m1 \\
\hline $\mathrm{Clqb}$ & Mm01179619_m1 \\
\hline $\mathrm{C} 1 \mathrm{qc}$ & Mm00776126_m1 \\
\hline $\mathrm{Ccl} 2$ & Mm00441242_m1 \\
\hline $\mathrm{Ccrl} 2$ & Mm00516914_g1 \\
\hline $\mathrm{Cd} 74$ & Mm00658576_m1 \\
\hline Chil3 & Mm00657889_mH \\
\hline Csf1 & Mm00432686_m1 \\
\hline Csf1r & Mm01266652_m1 \\
\hline Cst3 & Mm00438347_m1 \\
\hline Cst7 & Mm00438351_m1 \\
\hline Ctsz & Mm00517697_m1 \\
\hline Ctsb & Mm01310506_m1 \\
\hline Ctsd & Mm00515586_m1 \\
\hline Ctsl & Mm00515597_m1 \\
\hline Ctss & Mm01255859_m1 \\
\hline$A x \mid$ & Mm00437221_m1 \\
\hline $\mathrm{C} \times 3 \mathrm{cr} 1$ & Mm02620111_s1 \\
\hline Cyba & Mm00514478_m1 \\
\hline Eef1a1 & Mm01973893_g1 \\
\hline Egr1 & Mm00656724_m1 \\
\hline P2ry13 & Mm01951265_s1 \\
\hline F11r & Mm00554113_m1 \\
\hline Fcrls & Mm00472833_m1 \\
\hline Ftl1 & Mm03030144_g1 \\
\hline Fth1 & Mm00850707_g1 \\
\hline Golm1 & Mm00550918_m1 \\
\hline Gpr34 & Mm02620221_s1 \\
\hline Hexb & Mm01282432_m1 \\
\hline Hif1a & Mm00468869_m1 \\
\hline Kctd12 & Mm00624816_s1 \\
\hline Lag3 & Mm00493071_m1 \\
\hline Lyz2 & Mm01612741_m1 \\
\hline Mafb & Mm00627481_s1 \\
\hline Olfml3 & Mm00513567_m1 \\
\hline Pde3b & Mm00691635_m1 \\
\hline Plxdc2 & Mm00470653_m1 \\
\hline Sall1 & Mm00491266_m1 \\
\hline Slc11a1 & Mm00443045_m1 \\
\hline Slco2b1 & Mm00614448_m1 \\
\hline
\end{tabular}

Table 1 Gene names and TaqMan probes analyzed in this study. Genes in bold were run with individual probes: the rest were run together on TaqMan custom low-density array cards (Continued)

\begin{tabular}{ll}
\hline Gene & TaqMan probe \\
\hline Spp1 & Mm00436767_m1 \\
Tgfbr1 & Mm00436964_m1 \\
Tpt1 & Mm03009502_g1 \\
Tyrobp & Mm00449152_m1 \\
Mertk & Mm00434920_m1 \\
18S & Hs99999901_s1 \\
Clec7a & Mm01183349_m1 \\
P2ry12 & Mm00446026_m1 \\
Itgax & Mm00498701_m1 \\
Hprt & Mm00446968_m1 \\
\hline
\end{tabular}

ourselves and others [25, 28]. Additionally, we found that in the KI mice HHcy was associated with greater amyloid plaque burden in the cortex and hippocampus, as measured by $6 \mathrm{E} 10$ percent area positivity, and corresponding with an increase in the total number of plaques (Fig. 1a-c). In the cortex, average plaque number increased from 13.3 per $\mathrm{mm}^{2}(\mathrm{SD}=6.1)$ in KI mice on control diet to $29.4 \mathrm{~mm}^{2}(\mathrm{SD}=17.3)$ in those on HHcy diet. Hippocampal plaques increased from $3.9(\mathrm{SD}=3.3)$ to $10.1(\mathrm{SD}=8.7)$ per $\mathrm{mm}^{2}$ in mice on control or HHcy diet, respectively. No changes were detected in hippocampal or cortical levels of $A \beta 40, A \beta 42$, nor the $A \beta 42 / 40$ ratio as measured by ELISA (Fig. 1d-i). Notably, no evidence of cerebral amyloid angiopathy (CAA) was found.

Next, amyloid plaque size analysis was performed in cortex and hippocampus in two ways. First, plaques were binned into small $\left(10-300 \mu \mathrm{m}^{2}\right)$, medium (301$\left.900 \mu \mathrm{m}^{2}\right)$, and large sizes $\left(901+\mu \mathrm{m}^{2}\right)$, with average plaques $/ \mathrm{mm}^{2}$ in each bin compared across dietary conditions (Fig. 2a) [26]. This analysis showed an increase in smaller plaques in the cortex, consistent with increased plaque deposition (Fig. 2), as well as an increase in the medium-sized plaques possibly representing growth of extant plaques. The increase of plaque number in these bins did not reach statistical significance in the hippocampus. Next, cumulative probability distribution histograms were generated for plaque size in each dietary condition (Fig. 2b) [27]. In accordance with the binned data analysis, the distribution was significantly shifted leftward in the cortex of the HHcy versus the control KI group, indicative of a larger proportion of smaller plaques (Kolmogorov-Smirnov test, $p=.0078$ ). This was not significant in the hippocampus (Kolmogorov-Smirnov test, $p=0.78$ ). 
Comorbid amyloid and HHcy pathologies subtly enhance pro-inflammatory cytokine levels

To assess whether the increased amyloid plaque burden resulted in an exacerbation of pro-inflammatory responses, we measured levels of the inflammationassociated molecules CXCL1, CCL3, IL-33, TNF $\alpha$, IL-6, and IL-1 $\beta$ by multiplexed MSD ELISA (Fig. 3). The overall changes in the cytokines measured were modest with respect to either strain or diet. There was a significant main effect of genotype on CCL3 expression in the cortex $(F(1,35)=37, p<.0001)$ and hippocampus $(F(1$, $35)=45.04, p<.0001)$, with significant differences detected by Sidak's post hoc tests between KI and WT groups within both dietary conditions. This was also true of cortical IL-1 $\beta(F(1,35)=22.52, p<.0001)$. In the hippocampus, there was a significant main effect of genotype on IL-1 $\beta(F(1,35)=8.45, p=.0063)$ and also a significant main effect of diet $(F(1,35)=7.26, p=$ .0108). Sidak's post-hoc tests showed significant differences between the KI HHcy and WT HHcy groups as well as the KI HHcy and KI control groups (Fig. 3b). No significant differences were detected in levels of CXCL1, TNF $\alpha$, or IL-6 in either region as a function of genotype or diet, but there was a significant diet by genotype interaction detected in the hippocampal IL-33 data $(F(1$, $35)=5.08, p=.0306)$. Although the interaction was significant, post hoc tests for differences between KI and WT control or KI HHcy and KI control groups did not reach statistical significance.

\section{HHcy does not alter P2ry12 staining patterns in response to amyloid pathology}

We quantified cortical and hippocampal P2ry12 staining as a microglia-specific marker [29] (Fig. 4a) indicative of overall microgliosis without potential inadvertent measurement of infiltrating myeloid cells. There was a significant main effect of genotype on P2ry12 staining in the cortex $(F(1,29)=9.973, p=0.0037)$, but no differences found in the hippocampus (Fig. 4b). A modest decrease in P2ry12 staining was observed in the cortex of KI mice on HHcy versus control diet; however, the difference between KI mice on HHcy diet and KI mice on control diet was not statistically significant $(p=0.08)$.

Given the established downregulation of P2ry12 in plaque-associated microglia $[15,30]$, the subtle decrease in P2ry12 positivity in the cortex might be attributable either to a straightforward increase in plaque burden, to a further downregulation of P2ry12 in plaque-associated microglia when HHcy is present, or both. To clarify these possibilities, we performed spatial analyses of P2ry12 and 6E10 plaque staining. We found that the percent area double-positive for P2ry12 and $A \beta$ 6E10 staining was unaltered within cortex between $\mathrm{KI}$ control $(M=.018 \%, \mathrm{SD}=.015)$ and KI HHcy mice $(M=.018 \%$,
.012) $(t(18)=0.0897, p=0.9295)$. This was similarly true in the hippocampus of the KI control $(M=.013 \%, \mathrm{SD}=$ $.009)$ and HHcy mice $(M=.014 \%, \mathrm{SD}=.011)(t(18)=$ $0.1474, p=0.8843)$. To examine the relationship more closely, a spatial proximity analysis was performed around a subset of plaques in the cortex (Fig. 5a). Results were consistent with a lack of dietary effect on the spatial distribution of P2ry12 staining in response to amyloid plaques. This was true when assessed either by total \% positive area of P2ry12 staining (Fig. 5b) or average pixel intensity (Fig. 5c). The relative dearth of P2ry12 staining and intensity in the inner ring closest to the plaque is consistent with previous reports of P2ry12 downregulation near plaques $[15,30]$. Taken together, these data indicate that the small decline in overall cortical P2ry12 staining may be primarily attributable to an increase in overall plaque number.

\section{HHcy modifies microglia-associated gene expression in WT and KI mice}

To begin exploring possible additive or interactive gene expression changes that occur in the comorbidity context, we measured whole-tissue cortical changes across a panel of 50 genes implicated in microglial responses to amyloid pathology (Table 1). A subset of 8 randomly selected mice per group (32 total samples) were used for the gene expression analysis, with data normalized to the expression level of WT mice. Chil3 is excluded from statistical analysis because two of the samples did not show any detectable level of this gene (see supplement 3 for full dataset). We first assessed whether our panel, despite not being run on RNA extracted from purified microglial populations, could detect any of the expected increase in DAM markers and decrease in homeostatic markers in the KI control vs WT control comparison. We found that 6 genes were detectably altered (Fig. 6a). In line with expectations, the DAM markers Itgax and Cst7 were upregulated and the homeostatic markers Golm1 and Csf1r were downregulated. Interestingly, the homeostatic markers Fcrls and P2ry12 were found to be upregulated, which could be indicative of an overall increase in the number of microglia.

When comparing WT HHcy and WT control groups, we found 4 significantly upregulated DAM markers: Itgax, Cst7, Clec7a, and Tpt1 (Fig. 6b). To determine whether there was an overall increase in the DAM signal or evidence of unique transcriptional changes, we next compared the KI HHcy and KI control groups. Seven genes were significant within this comparison, and the average transcript levels of these genes across all 4 groups are displayed in Fig. 7a. Interestingly, not only some damage-associated genes (Lag3, Clec7a, Lyz2) but also putative homeostatic markers (C1qb, C1qc, Sall1, Csf1r) were upregulated in the comorbid condition 

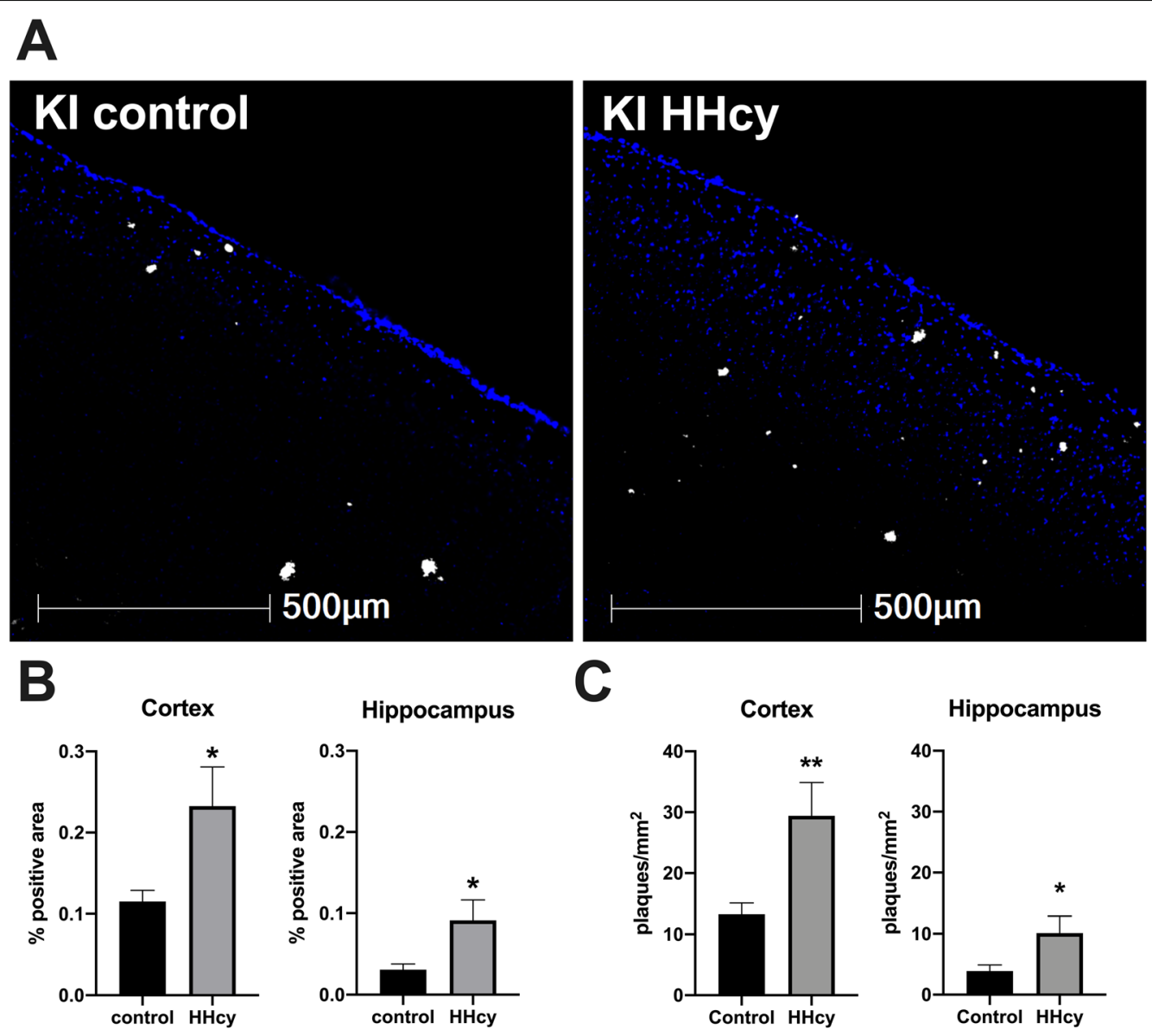

Hippocampus
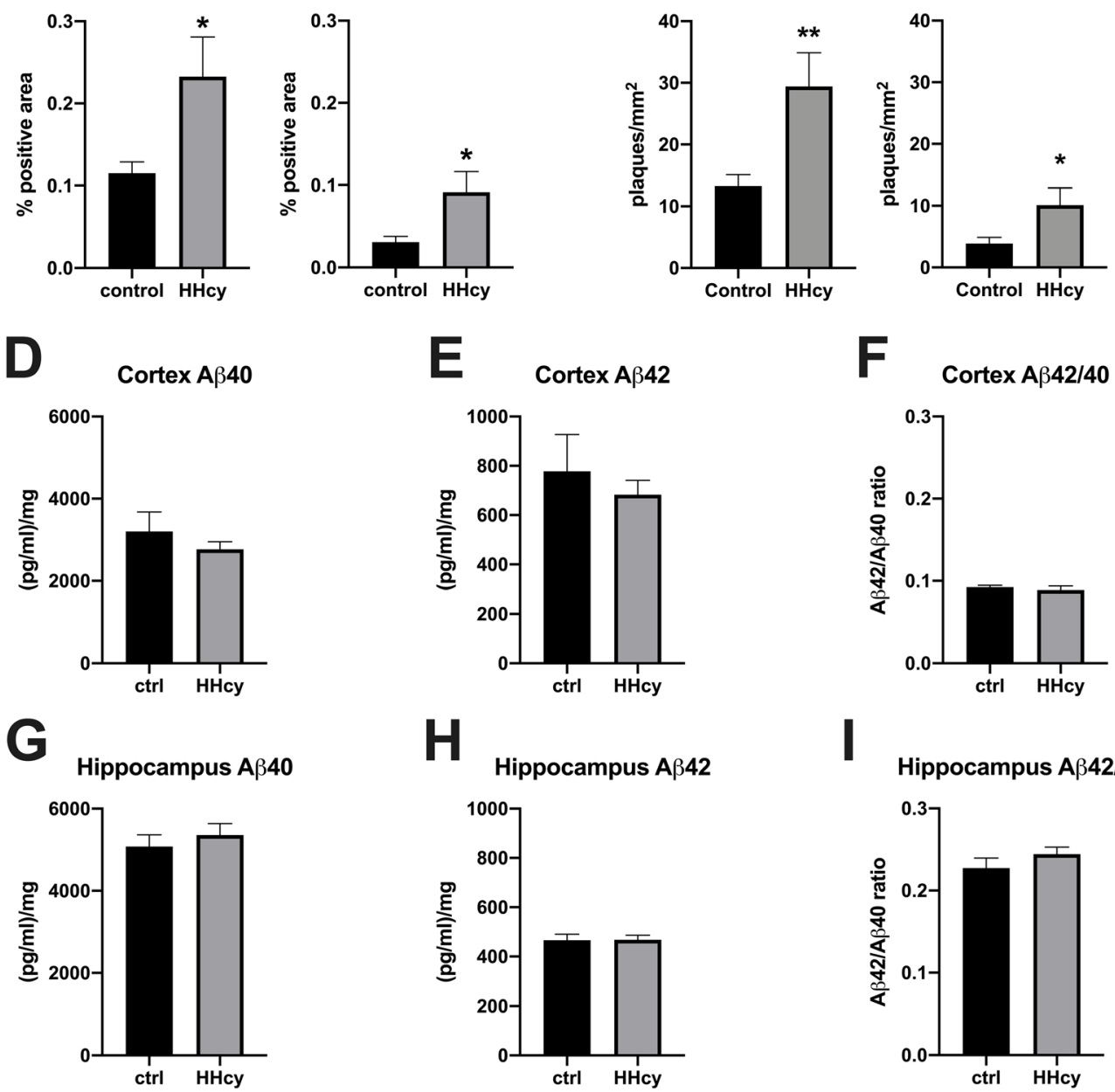

Fig. 1 (See legend on next page.) 
(See figure on previous page.)

Fig. 1 Dietary-induced HHcy is associated with increased cortical and hippocampal plaque burden in Kl mice. a Representative images of dorsal cortex from KI mice on control diet (KI control) or HHcy diet (KI HHcy). Nuclei were stained with DAPI and are shown in blue; amyloid beta plaques were stained with $6 \mathrm{E} 10$ antibody and are shown in white. b Total $6 \mathrm{E} 10 \%$ positive area within cortical and hippocampal ROls is quantified, showing a statistically significant increase in cortex and hippocampus. The increase in \% area positivity for 6 E 10 corresponded with an increase in the number of plaques per square millimeter in the cortex and hippocampus (c). Levels of soluble $A \beta 40, A \beta 42$, and the $A \beta 42 / 40$ ratios were unchanged in both the hippocampus and cortex $(\mathbf{d}-\mathbf{i}) .{ }^{*} p<.05$, ${ }^{* *} p<.01$, non-parametric Mann-Whitney $U$ tests

relative to the KI control group. A summary heatmap of $z$-scores with significant comparisons is shown in Fig. 7b. The full gene expression dataset is provided in supplement 3, and graphical representations of the processed data in supplement 4. These findings indicate that the comorbid pathologies have complex interactive effects in addition to straightforwardly additive ones. Replication and extension of these findings using unbiased whole-transcriptome analyses in isolated microglial (and other) cells will be an important next step in this line of research.

\section{Discussion}

We report here several major findings that increase our understanding of physiological changes occurring in the relatively common context of comorbid amyloid- and HHcy-associated pathologies, and also lay the groundwork for follow-up studies. First, 8 weeks of HHcyinducing diet is sufficient to produce a large increase in parenchymal plaque deposition, particularly smaller plaques, without a concomitant change in levels of soluble $A \beta$. This implies that interstitial levels of soluble $A \beta$ are being kept in equilibrium via increased plaque formation, consistent with the notion that sequestration into plaques can be a protective response against the more toxic soluble A $\beta$ species [31]. Our data align with the hypothesis that HHcy can enhance AD risk by increasing overall amyloid burden, a finding that has been replicated across models of AD and under different methods of HHcy-induction [21, 32-34]. Importantly, this appears reflective of what occurs in patient populations, where plasma $A \beta$ positively correlates with homocysteine levels and elevated Hcy is also associated with higher brain $\mathrm{A} \beta$ accumulation and CAA pathology [3538].

Second, HHcy in this model has a small effect on the pro-inflammatory milieu, at least in terms of the factors measured in this study. Partially this may be due to our focus on a limited subset of cytokines chosen primarily for reported responsiveness to amyloid pathology. Within this subset, there was only a modest proinflammatory cytokine response overall with CCL3 and IL-1 $\beta$ elevations driven by genotype. Only IL- $1 \beta$ was increased due to HHcy diet and even this effect was observed only within the hippocampus. Given the lack of a similar effect in the cortex, it appears that HHcy does not alter IL-1 $\beta$ levels primarily via increased amyloid. That the hippocampus is uniquely susceptible to exacerbated inflammatory responses in the comorbid context is intriguing and may be related to its sensitivity to vascular insults, particularly disruptions to the blood-brain barrier [39], which is a well-described feature of this particular model of HHcy [21, 25]. Interestingly, there was also a significant diet by genotype effect on hippocampal levels of IL-33, although the post hoc comparisons were non-significant potentially indicating a lack of adequate statistical power for this comparison. Biologically relevant changes in this pathway may be worth exploring in future experiments.

Overall, the cytokine data are consistent with previous studies that indicate an enhancement of proinflammatory responses in either WT or AD model mice in response to HHcy [20-22, 32]. Despite this, the magnitude of the effect appears to be much smaller in the present case, and there are several possibilities for this apparent discrepancy. Notably, the increase in plasma Hcy level was comparatively less severe in the present study. This might indicate that the pro-inflammatory response is graded depending upon the severity of induced HHcy. The implication of this scenario is that patients with severe HHcy may require treatments suppressing neuroinflammation; those with moderate HHcy may benefit more from alternative approaches. Alternatively, the discrepancy might simply be due to the method of cytokine measurement employed. Previous studies relied on transcriptional changes as indicative of cytokine modulation, but the present study more directly measured protein levels. Because cytokines are subject to complex regulation at many levels, large changes in cytokine mRNA transcripts may or may not represent changes at the functional protein level. For example, in a previous study that measured cortical IL- $1 \beta$ in this KI mouse strain, a 7 -fold increase in IL-1 $\beta$ mRNA occurred alongside a much more modest $20 \%$ increase in level of the mature protein [26]. Over-reliance on cytokine transcript levels without confirmation of protein changes may therefore overestimate or otherwise misrepresent the actual pro-inflammatory changes in a given brain region or pathological context. Such possibilities warrant more complete characterization of changes to the neuroinflammatory milieu occurring at 


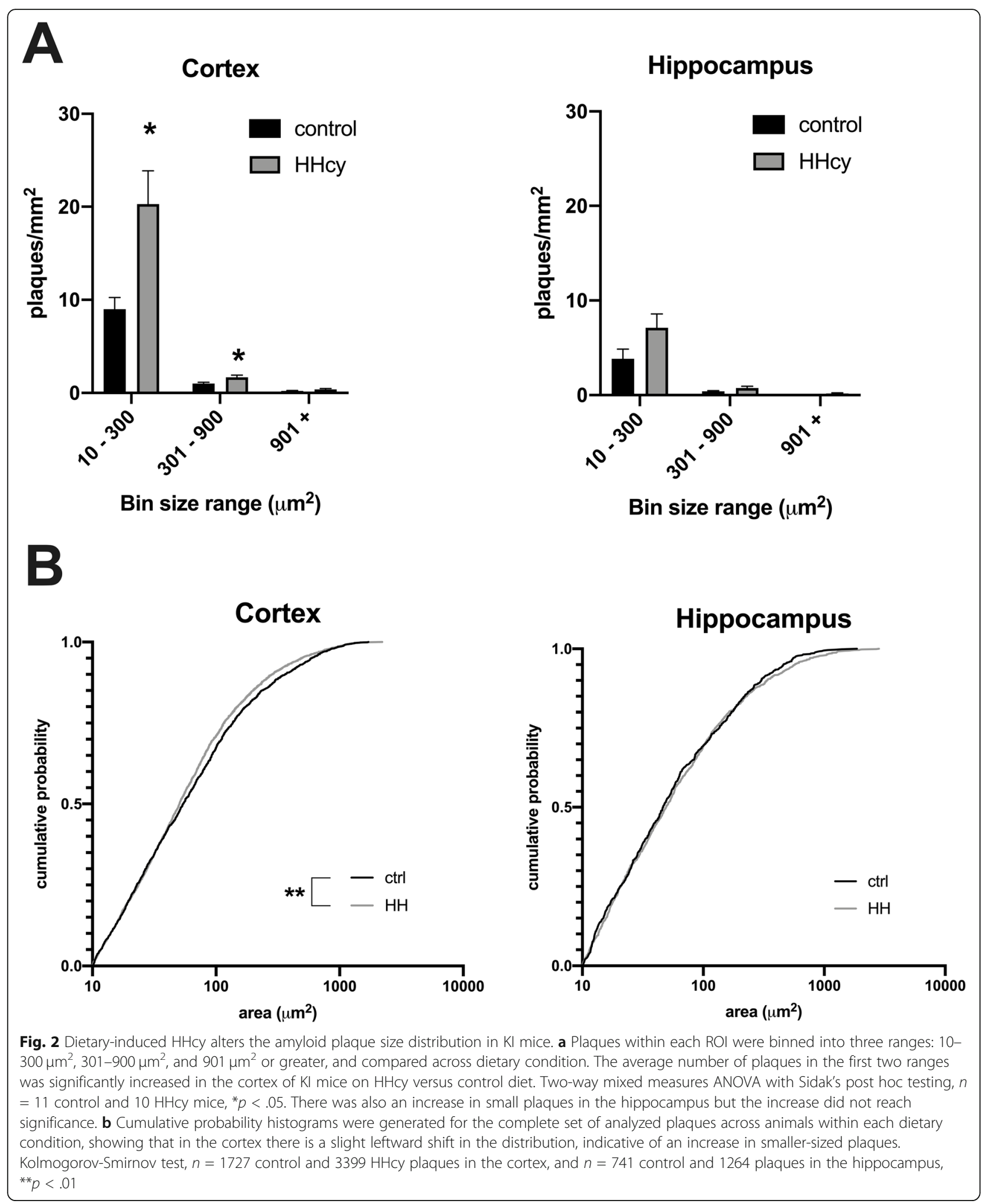

different levels of Hcy elevation, including the relevant transcriptional or translational regulatory mechanisms across contexts.
Although the neuroinflammatory response was relatively mild in this model, there were several important findings with regard to microglia. When P2ry12 staining 


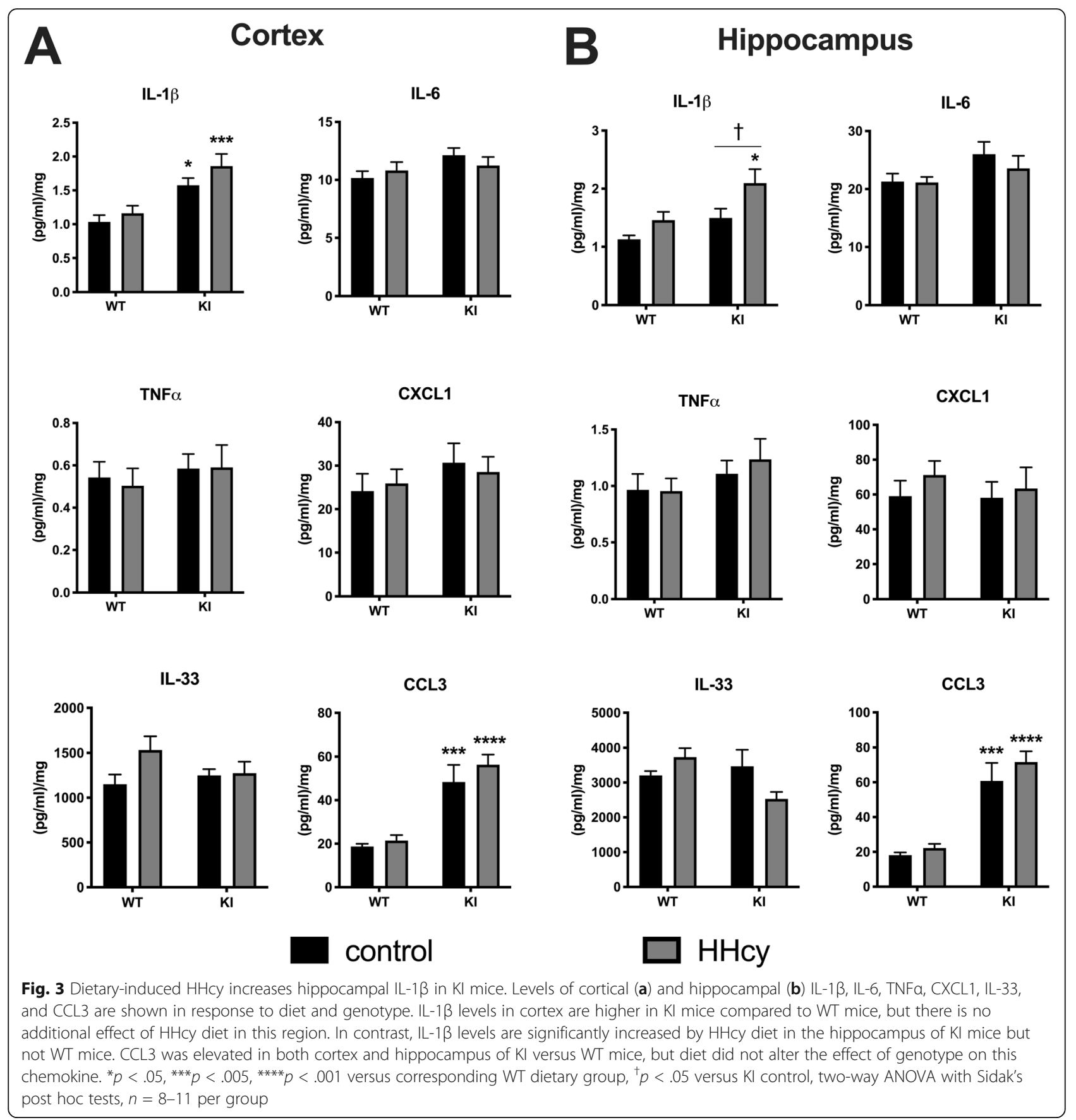

was taken as a marker of microgliosis, we observed the expected increase in staining within the cortex of KI versus WT mice, alongside a parallel increase in P2ry12 mRNA level. Interestingly, there was a moderate decrease in P2ry12 staining in the KI mice on HHcy diet relative to those on control diet. No such effect was observed in the WT animals, indicating that the reduction of P2ry12 staining in the comorbidity model might be primarily responding to the increase in plaque burden. Consistent with this, the expected downregulation of
P2ry12 staining as a function of proximity to plaques was observed $[15,30]$ and was unchanged by diet.

To further interrogate the relationship between these pathologies and microglial phenotype, a subset of microglia-enriched genes was evaluated. Fifty genes were selected, chosen based upon recently published datasets derived from microglia isolated from amyloidoverexpressing mice $[15,16]$. Half of the selected markers are positively regulated due to amyloid pathology and considered to be DAM markers. The other 


\section{A}
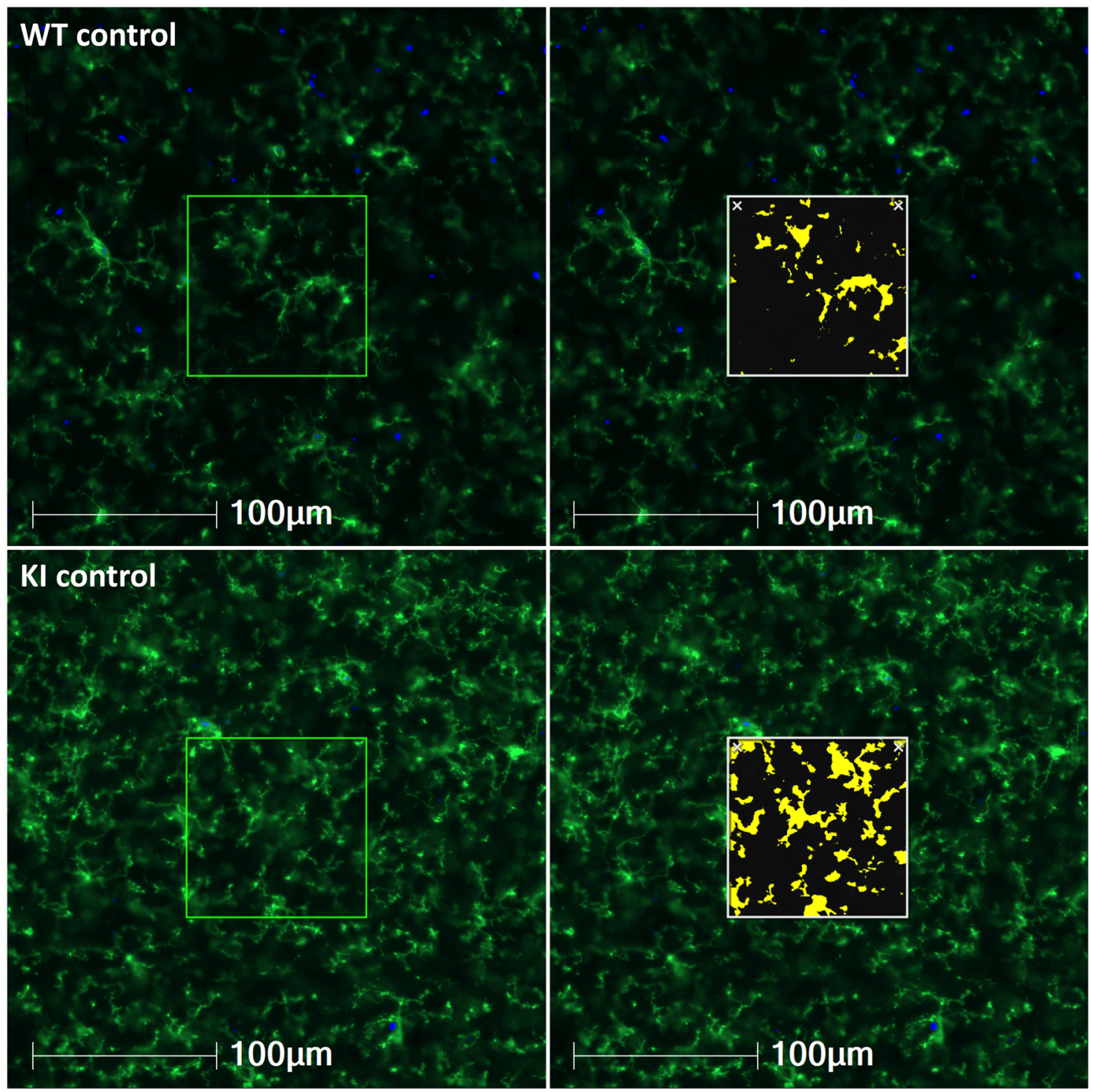

B

Cortex P2ry12

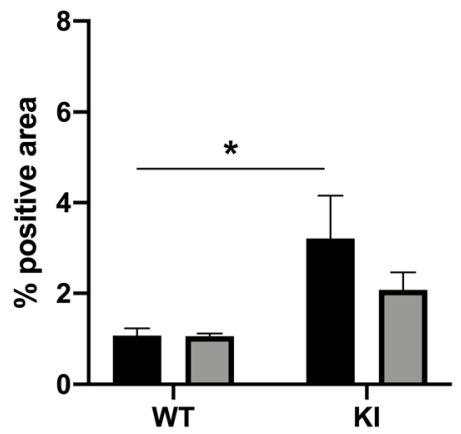

Hippocampus P2ry12

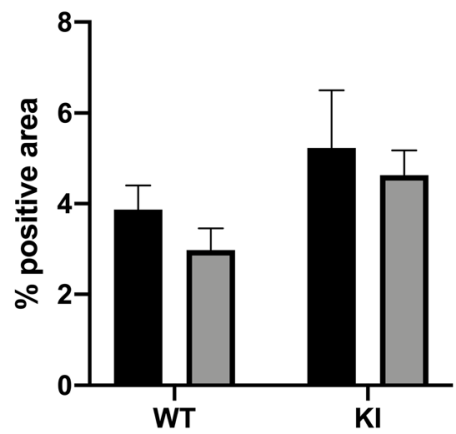

Fig. 4 (See legend on next page.) 
(See figure on previous page.)

Fig. 4 Dietary-induced HHcy is associated with a moderate decrease in cortical P2ry 12 staining in KI mice. Representative images of cortex from a WT mouse on control diet (WT control) and KI mouse on control diet (KI control) are shown in a, with P2ry12 in green and DAPI in blue. A measurement mask is shown with output of the analysis algorithm shown in yellow. Total \% positive area is quantified for the cortex and hippocampus in $\mathbf{b} .{ }^{*} p<.05$ versus WT control mice, two-way ANOVA with Sidak's post hoc tests, $n=7-10$ per group due to exclusion of slides with out-of-focus areas within the ROls

half are negatively regulated by amyloid pathology and considered to be homeostatic markers. We sampled both under the expectation of detecting an increase in some of the damage markers and a decrease in some of the homeostatic markers, which is precisely what we observed in comparisons between the KI control and WT control mice. The damage-associated genes Itgax and Cst7 were upregulated, and the homeostatic genes Golm1 and Csf1r were downregulated. Unexpectedly, the homeostatic genes P2ry12 and Fcrls were found to be elevated rather than reduced in the KI mice. This may be reflective of enhanced microgliosis in response to amyloid overshadowing more subtle effects occurring in the relatively small subset of plaque-associated microglia. That more genes were not detected as being significantly altered in our panel is likely due to some combination of a lack of a cell-specific signature, the attenuated amyloidosis that occurs in this model relative to the overexpression models more frequently utilized (e.g., $5 \mathrm{xFAD}$ mice), heterogeneity resulting from the use of a different background strain [40], or the unbalanced inclusion of both sexes and potentially increased biological variability of the sample. Although sex differences have not been studied in the KI mice, their existence is plausible given that sexual dimorphism has been observed in some other strains carrying APPswe/PS1dE9 mutations [41]. Further, we have found some indications that female mice might be differentially susceptible to

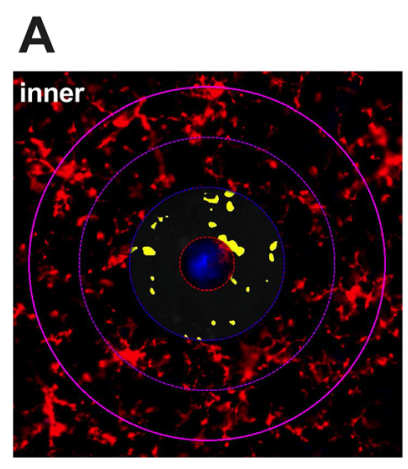

B

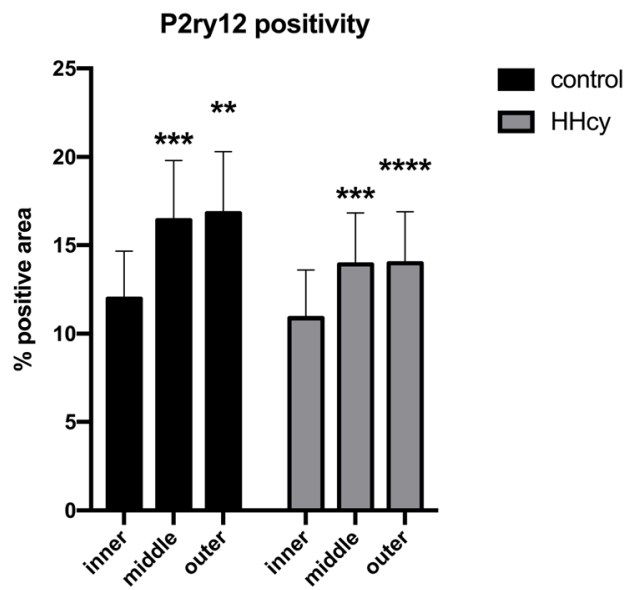

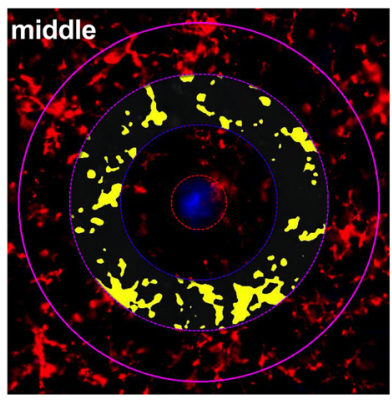

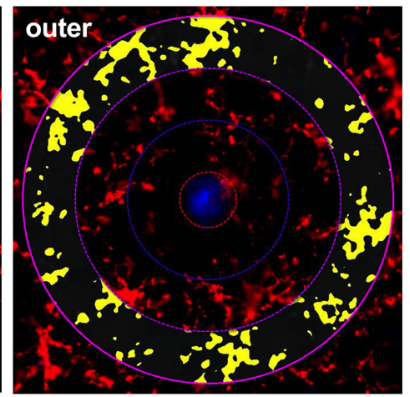

C

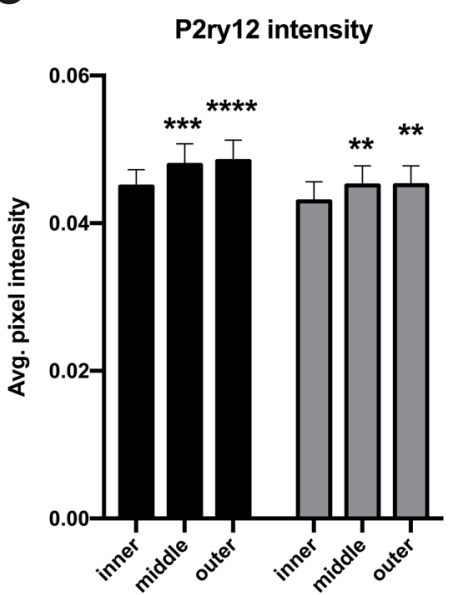

Fig. 5 Spatial analysis of P2ry12 positive microglia near plaques in Kl. Representative images of concentric, 30- $\mu$ m width analysis regions are shown in a where P2ry12 staining is in red, 6E10 staining is in blue, and output of the analysis algorithm is shown in yellow. Total \% positive area for P2ry 12 is quantified in $\mathbf{b}$, and average pixel intensity (AU) within each region shown in $\mathbf{c}^{* *} p<.01,{ }^{* * *} p<.005,{ }^{* * *} p<.001$ versus the inner ring within dietary groups. Two-way mixed measures ANOVA with Dunnett's post hoc tests 

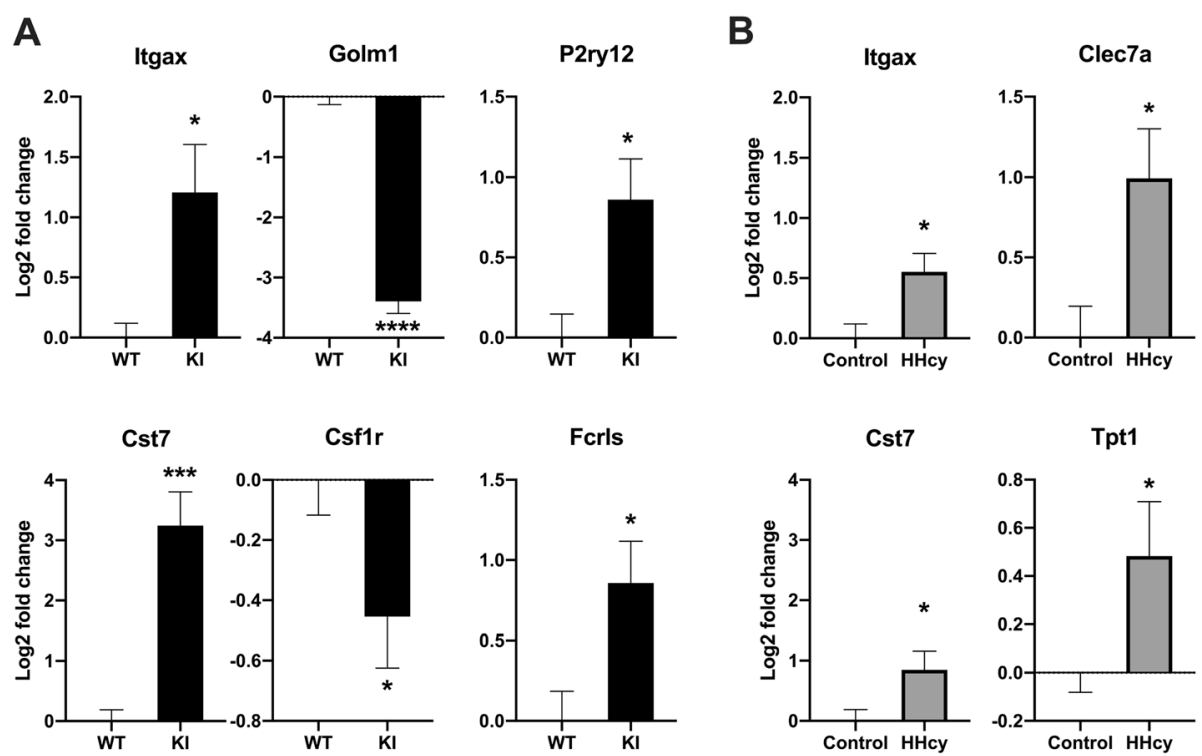

Fig. 6 Gene transcript levels are significantly altered in the single pathology amyloid or HHcy contexts. Gene transcripts significantly altered between KI mice on control diet and WT mice on control diet are shown in $\mathbf{a}$, and transcripts significantly altered between WT mice on HHcy diet and WT mice on control diet are shown in $\mathbf{b}$. Transcript fold changes are log2 normalized in comparison to the WT control diet condition. ${ }^{*} p$ $<.05,{ }^{* * *} p<.005,{ }^{* * * *} p<.0001$, multiple $t$ tests, uncorrected

the deleterious effects of this particular HHcy diet [25]. Given the sexual dimorphism that exists clinically in both $\mathrm{AD}$ and HHcy contexts, it will be important to isolate sex as a variable in future studies.

In addition to the transcripts responsive to amyloid, we found 4 responsive to HHcy diet in the WT mice: Itgax, Cst7, Clec7a, and Tpt1. That Itgax and Cst7 are upregulated due to HHcy as well as amyloid is consistent with the frequently described elevation of these genes across pathological contexts [42]. Clec7a is notable in that little response of this transcript was detectable in the KI control mice relative to WT control. Clec7a is a pathogen-associated molecular pattern receptor involved in the innate immune response, including microglial phagocytic responses [43], and it has been shown to increase in parallel with plaque burden in mouse models of $\mathrm{AD}$ [44]. The most parsimonious explanation for these data is that HHcy increases Clec7a mRNA in a wider population of microglia throughout the cortex, whereas plaque deposition is associated with increased Clec7a mRNA primarily in those microglia that are closely plaque-associated. When amyloid and HHcy cooccur, there may be both an increase in Clec7a mRNA across the wider microglial population, as well as an increase in the proportion of microglia that are plaqueassociated (due to the enhanced amyloid burden). Interestingly, Clec7a has been reported to respond to neuronal damage rather than the presence of $A \beta$ per se [15]. The HHcy diet may therefore be causing significant neuronal damage, and a closer examination of the effect of the HHcy diet on neuronal health and functioning in relationship to microglial parameters in both the WT and KI conditions should be investigated in future work. Tpt1 is a gene implicated in the cellular DNA damage response, known to be upregulated in the context of folic acid deficiency and homocysteine elevation (and amyloid itself) [45]. That this response was not observed in the KI mice with HHcy might be due to the preexisting pathway activation due to the presence of amyloid. Taken together, these data indicate that the gene expression panel is successfully detecting expected pathology-associated changes in gene expression levels when applied to the whole tissue.

Regarding the primary question of how microglia react in the comorbidity context, there are several possibilities that would predict different patterns in the data. For example, if the microglia were primarily responding to a straightforward increase in amyloid burden, then the prediction would be further upregulation or downregulation of the amyloid-associated transcriptional changes identified in the KI vs WT comparison. Evidence for this was not detected in the present study, and this could imply that certain microglial responses are already maximally engaged by one pathology or the other. Alternatively, overall plaque number may not be the primary driver of these shifts but, instead, levels of soluble $A \beta$ may be more important. There is also an indication that more of the microglia are in a DAM state when both pathologies are present, as some DAM transcripts not significantly elevated in either the HHcy or amyloid conditions 


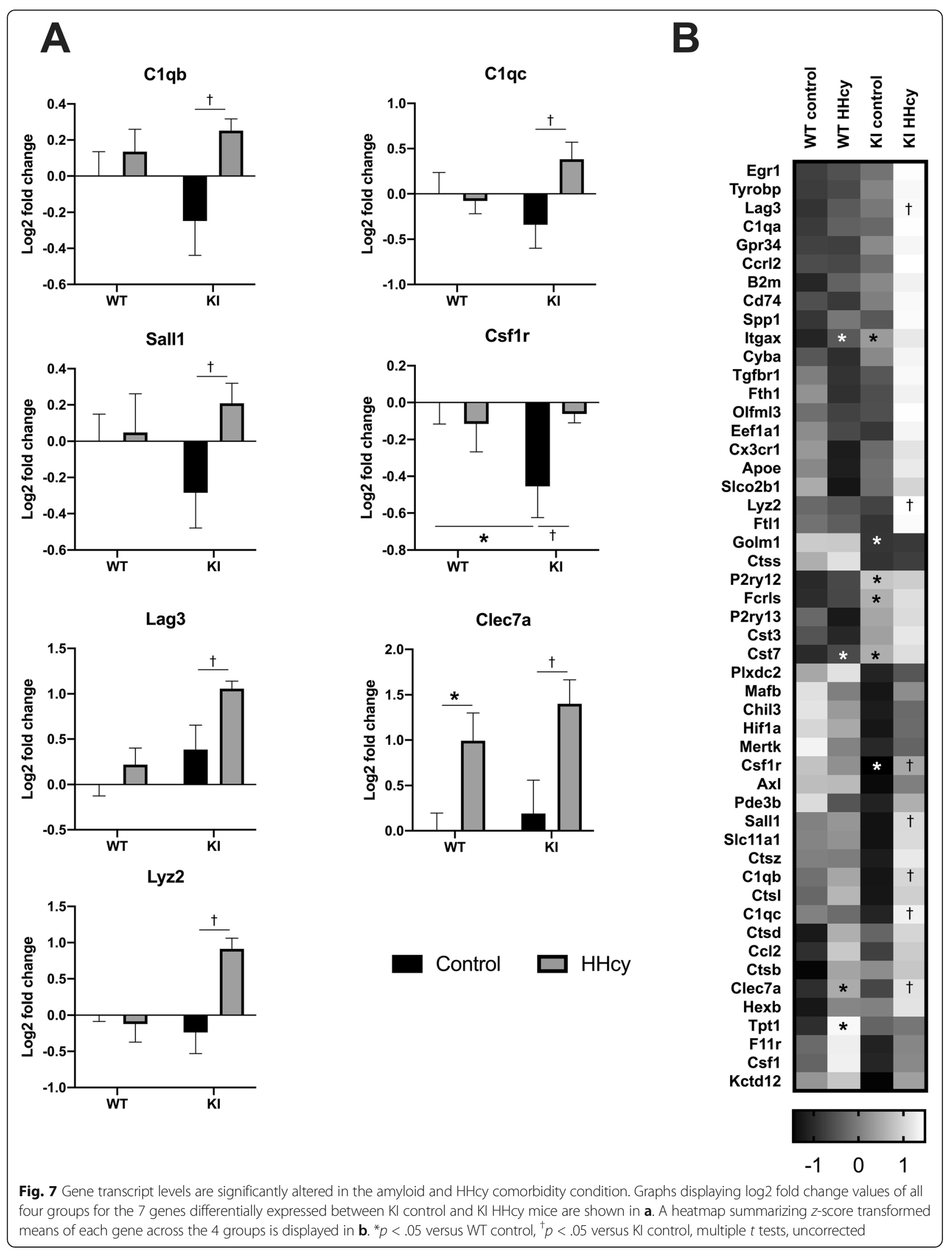


alone were detectably elevated only in the comorbid condition: Lag3 and Lyz2. Further, many other genes displayed that pattern even though statistical significance was not reached. Interestingly, several homeostatic genes showed a divergent directionality between the single factor pathologies and the comorbid condition, indicative of potentially interesting responses unique to the comorbid context: C1qb, C1qc, Sall1, and Csf1r.

$\mathrm{C} 1 \mathrm{qb}$ and $\mathrm{C} 1 \mathrm{qc}$ encode parts of complement component $1 \mathrm{q}(\mathrm{C} 1 \mathrm{q})$, which plays a critical role in synaptic pruning during development and in pathological conditions such as $\mathrm{AD}$ [46]. Although C1qa transcript levels were not significantly altered in any comparisons, the overall pattern suggests that there may be enhanced synaptic loss or neuronal dysfunction in the comorbid condition, a possibility worthy of exploration. Sall1 is a transcription factor that under physiological conditions inhibits microglial activation and pro-inflammatory responses [47]. Its upregulation in this context suggests reduced microglial reactivity to amyloid, and this may help to explain the modest effects on the pro-inflammatory cytokines measured. Csf1r signaling is well-characterized for its involvement in microglial proliferation and survival [48]. Recent studies have shown that chronic pharmacologic suppression of this receptor results in loss of microglia concomitant with protection against neurodegenerative changes in the 5xFAD amyloidosis model $[49,50]$, and its relative increase might be detrimental in this context. Although the specific implication of transcriptional changes in any particular gene is not clear, when taken together, these data indicate nonetheless that there exists both a potentiation of microglialassociated stress responses as well as more complex emergent responses in the comorbid $\mathrm{A} \beta$ and HHcy condition. Future studies utilizing more animals of both sexes, specific cellular isolation techniques, and unbiased measurement of whole-transcriptome changes will be useful in clarifying the microglia-specific alterations in this mixed pathology model. Ultimately, data must also be compared to samples from relevant patient populations to assess the external validity of the findings.

\section{Conclusion}

Modulation of microglial function represents a promising area for therapeutic development in Alzheimer's disease research. Given the frequent co-occurrence of multiple pathologies in patients with dementia, the success of this approach will likely require a deeper understanding of microglial responses in various contexts. The present study supports such efforts by offering an initial characterization of both general and unique microglialassociated changes in response to comorbid amyloidosis and HHcy. Whether successful treatments will focus on ameliorating general microglial dysfunction, will be tailored to specific responses, or both is an open question. The present study contributes to the groundwork necessary for future studies to explore this topic in more depth.

\section{Supplementary information}

Supplementary information accompanies this paper at https://doi.org/10. 1186/s12974-020-01938-7.

Additional file 1:. Supplemental figure 1: Tissue dissection and regions of interest for analyses.

Additional file 2:. Supplemental figure 2: HHcy model validation data.

Additional file 3:. Full gene expression raw dataset.

Additional file 4:. Full gene expression graphical dataset.

\section{Abbreviations}

Aß: Amyloid beta; AD: Alzheimer's disease; ANOVA: Analysis of variance; C1q: Complement component 1q; CAA: Cerebral amyloid angiopathy; Hcy: Homocysteine; HHcy: Hyperhomocysteinemia; Kl: Knock-in; MSD: MesoScale Discovery; PBS: Phosphate-buffered saline; qRTPCR: Quantitative reverse-transcriptase polymerase chain reaction; SD: Standard deviation; WT: Wildtype

\section{Acknowledgements}

We thank Amy Gorman, Danielle Goulding, and Alex Early for their technical assistance with this project.

\section{Authors' contributions}

DJB and LJVE designed research studies. DJB performed the experiment and harvested the tissue; performed qRT-PCR, AB ELISA, and tissue staining; analyzed the data; and wrote the manuscript. ED sectioned tissue and performed cytokine MSD ELISAs. JMM assisted with experimental design and data analysis. All authors read and approved the final manuscript.

\section{Funding}

This study was supported by National Institute on Aging Fellowship F32AG058456

\section{Availability of data and materials}

The datasets generated and analyzed for this study are available from the corresponding author upon reasonable request.

\section{Ethics approval and consent to participate}

All animal procedures for this study were approved by the Institutional Animal Care and Use Committee of the University of Kentucky.

\section{Consent for publication}

Not applicable.

\section{Competing interests}

The authors declare that they have no competing interests.

\section{Author details}

'Sanders-Brown Center on Aging, University of Kentucky, 101 Sanders-Brown Bldg., 800 S. Limestone Street, Lexington, KY 40536, USA. ²Department of Neuroscience, University of Kentucky, Lexington, KY, USA. ${ }^{3}$ Spinal Cord and Brain Injury Research Center, University of Kentucky, Lexington, KY, USA.

Received: 13 February 2020 Accepted: 24 August 2020

Published online: 17 September 2020

\section{References}

1. Nygard O, Refsum H, Ueland PM, Vollset SE. Major lifestyle determinants of plasma total homocysteine distribution: the Hordaland Homocysteine Study. Am J Clin Nutr. 1998;67(2):263-70. 
2. Price BR, Wilcock DM, Weekman EM. Hyperhomocysteinemia as a risk factor for vascular contributions to cognitive impairment and dementia. Front Aging Neurosci. 2018;10:350.

3. Selhub J. Homocysteine metabolism. Annu Rev Nutr. 1999;19:217-46.

4. Smith AD, Refsum H. Homocysteine, B vitamins, and cognitive impairment. Annu Rev Nutr. 2016:36:211-39.

5. Kuo HK, Sorond FA, Chen JH, Hashmi A, Milberg WP, Lipsitz LA. The role of homocysteine in multisystem age-related problems: a systematic review. J Gerontol A Biol Sci Med Sci. 2005;60(9):1190-201.

6. Selhub J, Jacques PF, Wilson PW, Rush D, Rosenberg $\Vdash H$. Vitamin status and intake as primary determinants of homocysteinemia in an elderly population. JAMA. 1993;270(22):2693-8.

7. Janson JJ, Galarza CR, Murua A, Quintana I, Przygoda PA, Waisman G, Camera L, Kordich L, Morales M, Mayorga LM, et al. Prevalence of hyperhomocysteinemia in an elderly population. Am J Hypertens. 2002; 15(5):394-7.

8. Alzheimer's Association: 2020 Alzheimer's disease facts and figures. [eBook]. Chicago; 2020. Retrieved from https://www.alz.org/media/Documents/ alzheimers-facts-and-figures.pdf.

9. Smith AD, Refsum H, Bottiglieri T, Fenech M, Hooshmand B, McCaddon A,

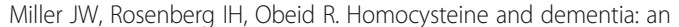
international consensus statement. J Alzheimers Dis. 2018;62(2):561-70.

10. Clarke R, Halsey J, Lewington S, Lonn E, Armitage J, Manson JE, Bonaa KH, Spence JD, Nygard O, Jamison R, et al. Effects of lowering homocysteine levels with B vitamins on cardiovascular disease, cancer, and cause-specific mortality: meta-analysis of 8 randomized trials involving 37485 individuals. Arch Intern Med. 2010;170(18):1622-31.

11. Jacques PF, Selhub J, Bostom AG, Wilson PW, Rosenberg $\mathbb{H}$. The effect of folic acid fortification on plasma folate and total homocysteine concentrations. N Engl J Med. 1999:340(19):1449-54.

12. Langa KM, Larson EB, Crimmins EM, Faul JD, Levine DA, Kabeto MU, Weir DR. A comparison of the prevalence of dementia in the United States in 2000 and 2012. JAMA Intern Med. 2017;177(1):51-8.

13. Obeid R, Herrmann W. Mechanisms of homocysteine neurotoxicity in neurodegenerative diseases with special reference to dementia. FEBS Lett. 2006;580(13):2994-3005.

14. Hemonnot AL, Hua J, Ulmann L, Hirbec H. Microglia in Alzheimer disease: wellknown targets and new opportunities. Front Aging Neurosci. 2019;11:233.

15. Krasemann S, Madore C, Cialic R, Baufeld C, Calcagno N, El Fatimy R, Beckers L, O'Loughlin E, Xu Y, Fanek Z, et al. The TREM2-APOE pathway drives the transcriptional phenotype of dysfunctional microglia in neurodegenerative diseases. Immunity. 2017;47(3):566-81 e569.

16. Keren-Shaul H, Spinrad A, Weiner A, Matcovitch-Natan O, Dvir-Szternfeld R, Ulland TK, David E, Baruch K, Lara-Astaiso D, Toth B, et al. A unique microglia type associated with restricting development of Alzheimer's disease. Cell. 2017;169(7):1276-90 e1217.

17. Wan L, Sun Y, Zhang F, Ren Y. Low-dose homocystine enhances proliferation and migration of BV2 microglia cells. Cell Mol Neurobiol. 2016; 36(8):1279-89.

18. Weekman EM, Woolums AE, Sudduth TL, Wilcock DM. Hyperhomocysteinemia-induced gene expression changes in the cell types of the brain. ASN Neuro. 2017;9(6):1759091417742296.

19. Chen S, Dong Z, Cheng M, Zhao Y, Wang M, Sai N, Wang X, Liu H, Huang G, Zhang $X$. Homocysteine exaggerates microglia activation and neuroinflammation through microglia localized STAT3 overactivation following ischemic stroke. J Neuroinflammation. 2017;14(1):187.

20. Sudduth TL, Powell DK, Smith CD, Greenstein A, Wilcock DM. Induction of hyperhomocysteinemia models vascular dementia by induction of cerebral microhemorrhages and neuroinflammation. J Cereb Blood Flow Metab. 2013;33(5):708-15.

21. Sudduth TL, Weekman EM, Brothers HM, Braun K. Wilcock DM: beta-amyloid deposition is shifted to the vasculature and memory impairment is exacerbated when hyperhomocysteinemia is induced in APP/PS1 transgenic mice. Alzheimers Res Ther. 2014;6(3):32.

22. Sudduth TL, Weekman EM, Price BR, Gooch JL, Woolums A, Norris CM, Wilcock DM. Time-course of glial changes in the hyperhomocysteinemia model of vascular cognitive impairment and dementia (VCID). Neuroscience. 2017;341:42-51.

23. Saito T, Matsuba Y, Mihira N, Takano J, Nilsson P, Itohara S, Iwata N, Saido TC. Single App knock-in mouse models of Alzheimer's disease. Nat Neurosci. 2014;17(5):661-3.
24. Flood DG, Reaume AG, Dorfman KS, Lin YG, Lang DM, Trusko SP, Savage MJ, Annaert WG, De Strooper B, Siman R, et al. FAD mutant PS-1 gene-targeted mice: increased A beta 42 and A beta deposition without APP overproduction. Neurobiol Aging. 2002;23(3):335-48.

25. Braun DJ, Abner E, Bakshi V, Goulding DS, Grau EM, Lin AL, Norris CM, Sudduth TL, Webster SJ, Wilcock DM, et al. Blood flow deficits and cerebrovascular changes in a dietary model of hyperhomocysteinemia. ASN Neuro. 2019;11:1759091419865788.

26. Bachstetter AD, Norris CM, Sompol P, Wilcock DM, Goulding D, Neltner JH, St Clair D, Watterson DM, Van Eldik LJ. Early stage drug treatment that normalizes proinflammatory cytokine production attenuates synaptic dysfunction in a mouse model that exhibits age-dependent progression of Alzheimer's disease-related pathology. J Neurosci. 2012;32(30):10201-10.

27. Liu P, Reichl JH, Rao ER, McNellis BM, Huang ES, Hemmy LS, Forster CL, Kuskowski MA, Borchelt DR, Vassar R, et al. Quantitative comparison of dense-core amyloid plaque accumulation in amyloid-beta protein precursor transgenic mice. J Alzheimers Dis. 2017:56(2):743-61.

28. Ernest S, Hosack A, O'Brien WE, Rosenblatt DS, Nadeau JH. Homocysteine levels in A/J and C57BL/6J mice: genetic, diet, gender, and parental effects. Physiol Genomics. 2005;21(3):404-10.

29. Butovsky O, Jedrychowski MP, Moore CS, Cialic R, Lanser AJ, Gabriely G, Koeglsperger T, Dake B, Wu PM, Doykan CE, et al. Identification of a unique TGF-beta-dependent molecular and functional signature in microglia. Nat Neurosci. 2014;17(1):131-43.

30. Jay TR, Miller CM, Cheng PJ, Graham LC, Bemiller S, Broihier ML, Xu G, Margevicius D, Karlo JC, Sousa GL, et al. TREM2 deficiency eliminates TREM2 + inflammatory macrophages and ameliorates pathology in Alzheimer's disease mouse models. J Exp Med. 2015;212(3):287-95.

31. Treusch S, Cyr DM, Lindquist S. Amyloid deposits: protection against toxic protein species? Cell Cycle. 2009;8(11):1668-74.

32. Weekman EM, Sudduth TL, Price BR, Woolums AE, Hawthorne D, Seaks CE, Wilcock DM. Time course of neuropathological events in hyperhomocysteinemic amyloid depositing mice reveals early neuroinflammatory changes that precede amyloid changes and cerebrovascular events. J Neuroinflammation. 2019;16(1):284.

33. Li JG, Pratico D. High levels of homocysteine results in cerebral amyloid angiopathy in mice. J Alzheimers Dis. 2015;43(1):29-35.

34. Li JG, Barrero C, Merali S, Pratico D. Five lipoxygenase hypomethylation mediates the homocysteine effect on Alzheimer's phenotype. Sci Rep. 2017;7:46002.

35. Luchsinger JA, Tang MX, Miller J, Green R, Mehta PD, Mayeux R. Relation of plasma homocysteine to plasma amyloid beta levels. Neurochem Res. 2007; 32(4-5):775-81.

36. Irizarry MC, Gurol ME, Raju S, Diaz-Arrastia R, Locascio JJ, Tennis M, Hyman BT, Growdon JH, Greenberg SM, Bottiglieri T. Association of homocysteine with plasma amyloid beta protein in aging and neurodegenerative disease. Neurology. 2005;65(9):1402-8.

37. Hooshmand B, Polvikoski T, Kivipelto M, Tanskanen M, Myllykangas L, Erkinjuntti T, Makela M, Oinas M, Paetau A, Scheltens P, et al. Plasma homocysteine, Alzheimer and cerebrovascular pathology: a populationbased autopsy study. Brain. 2013;136(Pt 9):2707-16.

38. Chung YC, Kruyer A, Yao Y, Feierman E, Richards A, Strickland S, Norris EH. Hyperhomocysteinemia exacerbates Alzheimer's disease pathology by way of the beta-amyloid fibrinogen interaction. J Thromb Haemost. 2016;14(7): 1442-52.

39. Nation DA, Sweeney MD, Montagne A, Sagare AP, D'Orazio LM, Pachicano M, Sepehrband F, Nelson AR, Buennagel DP, Harrington MG, et al. Bloodbrain barrier breakdown is an early biomarker of human cognitive dysfunction. Nat Med. 2019;25(2):270-6.

40. Onos KD, Uyar A, Keezer KJ, Jackson HM, Preuss C, Acklin CJ, O'Rourke R, Buchanan R, Cossette TL, Sukoff Rizzo SJ, et al. Enhancing face validity of mouse models of Alzheimer's disease with natural genetic variation. PLoS Genet. 2019;15(5):e1008155.

41. Li X, Feng Y, Wu W, Zhao J, Fu C, Li Y, Ding Y, Wu B, Gong Y, Yang G, et al. Sex differences between APPswePS1dE9 mice in A-beta accumulation and pancreatic islet function during the development of Alzheimer's disease. Lab Anim. 2016;50(4):275-85.

42. Dubbelaar ML, Kracht L, Eggen BJL, Boddeke E. The kaleidoscope of microglial phenotypes. Front Immunol. 2018;9:1753.

43. Shah VB, Huang Y, Keshwara R, Ozment-Skelton T, Williams DL, Keshvara L. Beta-glucan activates microglia without inducing cytokine production in Dectin-1-dependent manner. J Immunol. 2008;180(5):2777-85. 
44. Kamphuis W, Kooijman L, Schetters S, Orre M, Hol EM. Transcriptional profiling of CD11c-positive microglia accumulating around amyloid plaques in a mouse model for Alzheimer's disease. Biochim Biophys Acta. 2016; 1862(10):1847-60.

45. Kruman II, Kumaravel TS, Lohani A, Pedersen WA, Cutler RG, Kruman Y, Haughey N, Lee J, Evans M, Mattson MP. Folic acid deficiency and homocysteine impair DNA repair in hippocampal neurons and sensitize them to amyloid toxicity in experimental models of Alzheimer's disease. J Neurosci. 2002;22(5):1752-62.

46. Rajendran L, Paolicelli RC. Microglia-mediated synapse loss in Alzheimer's disease. J Neurosci. 2018:38(12):2911-9.

47. Buttgereit A, Lelios I, Yu X, Vrohlings M, Krakoski NR, Gautier EL, Nishinakamura R, Becher B, Greter M. Sall1 is a transcriptional regulator defining microglia identity and function. Nat Immunol. 2016;17(12):1397-406.

48. Chitu V, Gokhan S, Nandi S, Mehler MF, Stanley ER. Emerging roles for CSF-1 receptor and its ligands in the nervous system. Trends Neurosci. 2016;39(6): 378-93.

49. Sosna J, Philipp S, Albay R 3rd, Reyes-Ruiz JM, Baglietto-Vargas D, LaFerla FM, Glabe CG. Early long-term administration of the CSF1R inhibitor PLX3397 ablates microglia and reduces accumulation of intraneuronal amyloid, neuritic plaque deposition and pre-fibrillar oligomers in 5XFAD mouse model of Alzheimer's disease. Mol Neurodegener. 2018;13(1):11.

50. Spangenberg E, Severson PL, Hohsfield LA, Crapser J, Zhang J, Burton EA, Zhang Y, Spevak W, Lin J, Phan NY, et al. Sustained microglial depletion with CSF1R inhibitor impairs parenchymal plaque development in an Alzheimer's disease model. Nat Commun. 2019;10(1):3758.

\section{Publisher's Note}

Springer Nature remains neutral with regard to jurisdictional claims in published maps and institutional affiliations.

Ready to submit your research? Choose BMC and benefit from:

- fast, convenient online submission

- thorough peer review by experienced researchers in your field

- rapid publication on acceptance

- support for research data, including large and complex data types

- gold Open Access which fosters wider collaboration and increased citations

- maximum visibility for your research: over $100 \mathrm{M}$ website views per year

At $\mathrm{BMC}$, research is always in progress.

Learn more biomedcentral.com/submissions 